Volume: 01 Issue: 03 | Sep -2019

ISSN: $2663-8525$

Received: 19.08.2019; Accepted 23.08.2019; published: 30.09.2019 at www.editoncpublishing.org

Juma, D. Kimeli et al., Editon Cons. J. Arts., Humanit. S. Stud., Double -Blind Peer Reviewed Journal

\title{
Examining the Effect of Fellowship Groups' Interpersonal Relationships on Church Development in the African Gospel Church
}

\author{
David Kimeli Juma'; Nason Vundi²; Ndungu Ikenye ${ }^{3}$ \\ ${ }^{123}$ St. Paul's University, Kenya \\ Email address: goakims@yahoo.com
}

\begin{abstract}
The purpose of this study was to assess the effects of interpersonal relationship on church development. The study was built on Lewin's theory of change and Stakeholders theory by Freeman. Descriptive research design was used to determine the effects of variables. The target population was the fellowship, church leaders and members of fellowship groups in AGC churches Anaimoi sub-county, Kericho County, Kenya. Anaimoi is divided into 6 wards with each having an average of 10 AGC churches. The fellowship groups in 18 churches were used as a sample. Strata random sampling was used to select the respondents. Data was collected using structured questionnaires and interviews. The study was analysed through descriptive statistics with the help of SPSS and presented in pie charts, tables and graphs. Interpretation was made based on research objective. A pilot study was carried out by choosing one small group fellowship to determine the reliability and validity of research instruments. Cronbach's alpha technique was also used to test the reliability of the questionnaires' items. Multiple regression models were used to test the relationships between the study variables. Results indicated that there was a positive relationship between Fellowship Groups' Interpersonal Relationships and Church Development as the reported $p$ value is higher than the critical value. Another aspect that was observed was that the fellowship groups had manageable number of members in the fellowship that blended easily and form trust among them. The working together as a team was greatly enhanced where a member of the fellowship groups was involved in the operations. The fellowship groups act as cornerstones of progressive management for the foreseeable future.
\end{abstract}

Key Terms: interpersonal relationship, development, fellowship groups, small group

How to cite this article in APA $\left(6^{\text {th }}\right.$ Edition)
Juma, D. K. ; Vundi, N.; Ikenye, N. (2019). Examining the effect of fellowship groups' interpersonal
relationships on church development in the African Gospel Church. Editon Cons. J. Arts., Humanit.
S. Stud., $1(1), 68-80$.




\section{Editon Consortium Journal of Arts, Humanities and Social Studies (ECJAHSS)}

Volume: 01 Issue: 03 | Sep -2019

ISSN: $2663-8525$

Received: 19.08.2019; Accepted 23.08.2019; published: 30.09.2019 at www.editoncpublishing.org

Juma, D. Kimeli et al., Editon Cons. J. Arts., Humanit. S. Stud., Double-Blind Peer Reviewed Journal

\section{Introduction}

Africa Gospel church (AGC) traces its origin to the work of Willis Hotchkiss missionary in 1905 and World Gospel Mission. Since then, the church has witnessed remarkable growth and development in rural and urban areas in Kenya, Uganda, Tanzania, and South Sudan. The church embraces small fellowship to do ministry and carry out her mission. These groups play major role AGC's ability to continually grow and transform communities. The church is a sponsor to a number of institutions in the country including Kenya Highlands Evangelical University, Tenwek Hospital, Tenwek School of Nursing, bible colleges, Ministry Training Institutes, Primary and Secondary Schools and community development projects (Africa Gospel Church, 2018).

AGC as one of the largest evangelical denomination in Kenya has a stucure which has discipleship leaders in charge of fellowship groups from the national level to the local churches( African Gospel Church, 2018). From its registration as an autonomus entinty in August 1961 the church has grown to over 1700 congregations spread in different parts of the country (African Gospel Church, 2018). This has seen remarkable growth and development in rural and urban areas as well as sending missionaries to least reached communitites in Kenya, Uganda, Tanzania and South Sudan. While the groups conceptsseem to be fragmenting churches, the AGC church seem to be growing stronger through fellowship groups. It's however imporatnt to note that the extent of contribution of these groups towards churchdevelopment has not been given much attention. It is therefore against this background that this study seeks to evaluate the role offellowshipgroupsin church development, with a focus on Africa Gospel Churches (AGC).
According to Howerton and Manning (2012), fellowship groups is a micro-community of 3-12 followers of Christ doing life together. Rick Warren (2018) defines fellowship groups as a collection of Christians working on some common goals where they learn and share experiences together in a free atmosphere. According to Gerald (2014), the groups exist to stimulate the development of Christians to love God, connect to people relationally by serving, supporting, encouraging and to glorify God by make disciples of all nations (Matt 28:19-20). Carl (2012) noted that the fellowship group work so effectively in large churches and should be adapted to work in any size church in North America or overseas.

The pace of change in organizations today is increasingly becoming fast and unpredictable. According to Markus (2015) organizations that are looking for the pace of change to slow are likely to be disappointed. Organizations have to cope with changes in technology that has caused a revolution in the way business contact each other, sources for goods, information and even expertise knowledge.As the organization grows it requires restructuring of the systems to accommodate the growth. The convectional levels of customer satisfaction are changing. As the world evolves, customer needs has changed.Stronger economies are emerging leading to increased demand for products and services (Bellany, 2015). This means that companies must consider expansion that may involve addition of staffs and new facilities. These changes offer opportunities for staff to develop but also create more problems as companies find themselves needing to make difficult decisions, that can impact employee salaries and benefits 


\section{Editon Consortium Journal of Arts, Humanities and Social Studies (ECJAHSS)}

Volume: 01 Issue: 03 | Sep -2019

ISSN: $2663-8525$

Received: 19.08.2019; Accepted 23.08.2019; published: 30.09.2019 at www.editoncpublishing.org

Juma, D. Kimeli et al., Editon Cons. J. Arts., Humanit. S. Stud., Double -Blind Peer Reviewed Journal

and even threaten their jobs.There is need for ability to manage both ends of the spectrum. The Organizational dymamics is important particulary for organizations that want to maintain a strong brand and strong relationship with customers and employees.

In order to achieve the level of capability demanded from organizations today, organizations must embrace development as part and parcel of their proccesses. Organizational development (OD) according to Abraham, (2014) is the study of successful organizational change and performance. The concept emerged from human relations studies in the 1930s. This was after the realization that organizational structures and processes influenced worker behaviours and motivation. The concept has later on expanded to focus on aligning organizations with rapidly changing and complex environements. Key concept in organizational development is what influences collective behaviours, a key area of focus in the current study.

AGC while on its path to growth has adopted small group formations, which has seen it grow branches in Kenya and outside, while this effort can be commendable, inadequate research and focus given to the area, threatens the gains that the church has made in organizational development. The need for effective small group ministry is implied in the New Testament. If the local church is to truly develop the spiritual gifts of its members, and mobilize the terrific power of the Holy Spirit to work through a trained and experienced laity, if it is to facilitate true relationship-based community, it will need to organize smaller groups where these can be fostered.

\section{Literature Review}

Fellowship groups interpersonal relationships and church development

Interpersonal relationships in the group are an inescapable reality for all those working in organizations. While they have often been studied from a negative perspective, for many these relationships may facilitate a context in which working individuals can fulfil their "need to belong" (Saim, Cemberci, \& Gunel, 2015). Performance of members of any organization depends on the ability to effectively interact with their superiors, subordinates and co-workers within the organization and consumers, suppliers and general public outside. Interpersonal relations, therefore is a very important issue involving any organization. Most organizations have people problems rather than business problems. People problems are due to faulty interpersonal relations, which hinder the attainment of organizational goal (Patricia, 2016). Good communication within fellowship group helps members to avoid misunderstanding. The theories mentioned above have been quite successful in defining a number of potential variables and processes that characterize effective leadership. However, these models have not applied a multilevel approach to leadership, assuming that the process of leadership is relatively similar at all group echelons.

According to Gallos and Bass (2003) poor communication within groups may lead to broken relationships hence hindering the spirit of participation and collaboration. On the other hand, good communication increases understanding within the group members even as they serve together. One of the main benefits of having fellowship groups is that these groups are able to meet the 


\section{Editon Consortium Journal of Arts, Humanities and Social Studies (ECJAHSS)}

Volume: 01 Issue: 03 | Sep -2019

ISSN: $2663-8525$

Received: 19.08.2019; Accepted 23.08.2019; published: 30.09.2019 at www.editoncpublishing.org

Juma, D. Kimeli et al., Editon Cons. J. Arts., Humanit. S. Stud., Double -Blind Peer Reviewed Journal

interpersonal needs. This is because members feel included in the process of decision-making. If there are carrying out certain projects in the church, they fully participate at every stage because the own it. In this case they work is done smoothly, where each member of the group is playing their role because they feel they belong. It is also important to note that people have always lived in-group. A good example is families, friends, working groups who share the same values systems, loving, caring and providing for each other for strengthening each other for the benefit of the group. This brings about unity and harmony in the fellowship groups. The other positive element of fellowship group is that each member has the opportunity to share their views. This brings in the value of each member feeling that they have something to offer, use their talents, gifts and skills to serve. Some people join the group because they want to serve, other wants to be supported to use their time and other resources for the welfare of their fellowship groups. It is in the fellowship meetings where the members discover and grow their talents as they serve together. Patricia (2016) argues that some people with the similar issues may join the group not for financial support by more because they are seeking emotional support. In the same way apart from fellowship members serving together, they provide emotional support in fellowship meeting where they support, encourage and share their experiences together.

Baird (2018) found out that being part of a small group helps in reducing stress since members share their needs in a free environment and help each other. There are many actors in this system and they all are correlated with each other by many relationships. Positive leadership approaches are defined by their focus on positive capabilities that can be measured, developed and which lead to performance improvement, and by the inclusion of the positive group context that leaders foster (Luthans, \& Church, 2002). Leaders play important roles in enabling extraordinary performance through positively deviant behaviours. It is not just to create positive emotions in people. Positively deviant leadership places an emphasis on "what elevates individuals and groups (in addition to what challenges them), what goes right in groups (in addition to what goes wrong), what is life-giving (in addition to what is problematic or life-depleting), what is experienced as good (in addition to what is objectionable), what is extraordinary (in additions to what is merely effective), and what is inspiring (in addition to what is difficult or arduous)". Positively deviant leadership is associated with the promotion of outcomes such as interpersonal flourishing, meaningful work, virtuous behaviours, positive emotions, and energizing networks (Cameron, 2012, p. 2). In relation to the study, both church and fellowship leaders and have great influence on interpersonal relationships even in their different roles

That sense of belonging iskey and helps people to live a stress-free life. If there is a good interpersonal relationship between the individuals in the group, then the members will have a good time. For example, leaders that are perceived to be good listeners have been associated with employees feeling a sense of togetherness, belonging, social significance as well as inclusion (Alvesson, \& Swevingsson, 2003). A group with good interpersonal relationships will enhance unity among the members. Unity in turn promotes teamwork which aid in the development agenda of the organization (Reich, \& Herschcovis, 2011). Members who relate well with each other will work 


\section{Editon Consortium Journal of Arts, Humanities and Social Studies (ECJAHSS)}

Volume: 01 Issue: 03 | Sep -2019

ISSN: $2663-8525$

Received: 19.08.2019; Accepted 23.08.2019; published: 30.09.2019 at www.editoncpublishing.org

Juma, D. Kimeli et al., Editon Cons. J. Arts., Humanit. S. Stud., Double -Blind Peer Reviewed Journal

together in unity and will most of the time consult each other. This is aided by understanding among the members.

It is common to find that fellowship groups with poor interpersonal relationship being rocked with conflicts most of the time and this slows down the development process in church organization. A good interpersonal relationship among group members also contributes more in the decision-making process of the group members. In an organization decision-making is a process that most of the time requires more than one person. When members of the team have good interpersonal relationships, it follows that they freely express their views, which will aid decisionmaking process. Decision made will be objective and for the common good of all in the organization. These decisions will have been thoroughly thought through and will be made after careful considerations and deliberations. Such decisions help churches to move forward towards attaining their goals and objectives.

Contrary, poor interpersonal relationships negatively affect the decision-making process thus affecting productivity of the organization (Patricia, 2016). The decision making will take long time and will be marred with conflicts hence the development objectives may not be realized in good time. Interpersonal relationships play a part in either motivating or discouraging members. Members who relate well will be able to offer emotional support to each other and thus boost the morale of the team. A morally boosted group is more effective as they work with a lot more enthusiasm as opposed to a group, which is not motivated at all. Another area where the effect of interpersonal relationships is felt is when it comes to accomplishment of tasks (Patricia, 2016). Teams with good interpersonal relationships accomplish tasks in time as compared to the reverse group. Inter personal relationship create harmony among members and the leadership team by enhancing clear communication throughout the organization. In relation to the study, the fellowship members and the leaders will have clear understanding in relation to which role each group needs to perform to promote church development. This enhances members to meet deadline as each member will be working and playing their own part so that by the end all people will have substantially contributed for the good of all. Group communication ensures that each person is doing the right thing at the right time and they help one another. This in turn promotes the development of the organization.

According to Levi (2001), culture has three levels, the surface, deeper and deepest levels. On the surface culture depicts symbols and rituals, while on the deeper level, it is displayed in the styles and approaches used by group members when they interact with each other, for the examples how they solve conflicts whenever they arise. In the deepest level culture, consist of core ideologies, values and beliefs held in common by members. Levi farther argued that the measurement of group dynamics is essential in understanding the behaviour of individuals as well as that of the group as a whole (Levi, 2001).

While arguing on the same, Toseland and Rivas (2001) suggests that communication involves members, being encouraged to communicate among themselves other than leaders alone, which promote healthy discussion among them. It also ensures that members have input in the agenda of the group meetings and the direction in which they group needs to take. This enhances collaboration and 


\section{Editon Consortium Journal of Arts, Humanities and Social Studies (ECJAHSS)}

Volume: 01 Issue: 03 | Sep -2019

ISSN: 2663-8525

Received: 19.08.2019; Accepted 23.08.2019; published: 30.09.2019 at www.editoncpublishing.org

Juma, D. Kimeli et al., Editon Cons. J. Arts., Humanit. S. Stud., Double -Blind Peer Reviewed Journal

recognition of special skills and talents. In this way, members are rewarded for active involvement through appreciation and recognition (Toseland, \& Rivas, 2001).

\section{Methodology}

The study adopted a descriptive research design. The target population for this study was the fellowship members, their leaders and AGC pastors' ofAinamoi. According to data at AGC office Ainamoi has 60 churches with each church having an average of 3-4 small groups. The study focused on AGC churches in Ainamoi sub-county, Kericho County that has 6 wards according to office data. The stratified sampling method used to sample the fellowships groups in 18 AGC Churches. The total respondents were 138 . The sample respondents per ward were 23 respondents. Therefore, among the three churches per ward, each church had approximately 3 respondents. The study used random sampling to pick the sample churches per ward. This was done by listing down on a paper the names of the churches per ward and randomly picking 3 samples. This study used systematic random sampling to select sample small fellowship group per church. The researcher picked these by having a list of the small groups per church and randomly picked one fellowship group at intervals. The leader of that selected small fellowship group was interviewed. This formed a sample size of 138 respondents. The study used both quantitative and qualitative type of study. For the quantitative study, structured questionnaire was used to collect data. The researcher carried out a pilot study by administering a few questionnaires to respondents who will not form part of the respondent for the study. The pilot study conducted in Malava helped to clearly show that the research instruments were clear and perfect for the study. Cronbach's alpha technique was used to test the reliability of the research questions. An alpha value of 0.7 and above was used to decide on the reliability of the questionnaire items. The study collected both primary and secondary data. The data collected was coded and recorded in Statistical Package for Social Sciences (SPSS). An analysis was conducted to generate both descriptive and inferential statistics. Under descriptive statistics, parameters such as mean, standard deviation, frequency and percentages were generated. Under inferential statistics coefficients of regression was obtained to determine the relationship between data variables. Quantitative data analysis entailed summarising of study responses using numerical figures to generate statistical parameters such as mean, percentages, frequency, standard deviation and correlation analysis. Pearson chi square was used to find the significant level. Qualitative data was analysed through grouping the study responses into themes and discussion common themes emanating from the responses. The output of the study findings was presented in form of tables, graphs and charts. 


\section{Editon Consortium Journal of Arts, Humanities and Social Studies (ECJAHSS)}

Volume: 01 Issue: 03 | Sep -2019

ISSN: 2663-8525

Received: 19.08.2019; Accepted 23.08.2019; published: 30.09.2019 at www.editoncpublishing.org

Juma, D. Kimeli et al., Editon Cons. J. Arts., Humanit. S. Stud., Double -Blind Peer Reviewed Journal

\section{Findings and Data Analysis}

Table 1: To examine the effect of fellowship group's interpersonal relationships on church development

\begin{tabular}{|c|c|c|c|c|c|c|c|c|c|c|c|c|}
\hline \multirow{2}{*}{$\begin{array}{l}\text { Fellowship Group } \\
\text { interpersonal } \\
\text { relationship }\end{array}$} & \multicolumn{2}{|c|}{ 1-SA } & \multicolumn{2}{|l|}{$2-A$} & \multicolumn{2}{|c|}{$3-\mathrm{N}$} & \multicolumn{2}{|c|}{ 4. D } & \multicolumn{2}{|c|}{ 5-SD } & \multirow[t]{2}{*}{$\mathrm{m}$} & \multirow{2}{*}{ SD } \\
\hline & $\mathrm{F}$ & $\%$ & $\mathrm{~F}$ & $\%$ & $\mathrm{~F}$ & $\%$ & $F$ & $\%$ & $\mathrm{~F}$ & $\%$ & & \\
\hline $\begin{array}{l}\text { Fellowship based in } \\
\text { common shared } \\
\text { interest has enhanced } \\
\text { overall growth of the } \\
\text { church }\end{array}$ & 98 & 81.2 & 22 & 18 & 1 & 0.8 & 0 & 0 & 0 & 0 & 3.57 & 0.974 \\
\hline $\begin{array}{l}\text { The interrelationship } \\
\text { between group } \\
\text { members is based on } \\
\text { love }\end{array}$ & 70 & 57.9 & 47 & 38.7 & 2 & 1.7 & 2 & 1.7 & 0 & 0 & 3.49 & 1.353 \\
\hline $\begin{array}{l}\text { Fellowship is based on a } \\
\text { combination of love, } \\
\text { social commitment and } \\
\text { business interaction }\end{array}$ & 67 & 55.3 & 46 & 38 & 6 & 5 & 2 & 1.7 & 0 & 0 & 3.61 & 0.904 \\
\hline $\begin{array}{l}\text { Fellowship group has } \\
\text { enhanced growth and } \\
\text { development in the } \\
\text { church }\end{array}$ & 85 & 70.3 & 31 & 25.6 & 4 & 3.3 & 1 & 0.8 & 0 & 0 & 3.61 & 0.904 \\
\hline $\begin{array}{l}\text { Interpersonal } \\
\text { relationships have } \\
\text { affected the level of } \\
\text { influence towards } \\
\text { church activities }\end{array}$ & 81 & 67 & 38 & 31.4 & 1 & 0.8 & 1 & 0.8 & 0 & 0 & 3.61 & 0.904 \\
\hline $\begin{array}{l}\text { Type of interpersonal } \\
\text { relationships largely } \\
\text { contribute towards } \\
\text { church development }\end{array}$ & 81 & 67 & 38 & 31.4 & 1 & 0.8 & 1 & 0.8 & 0 & 0 & 3.49 & 1.353 \\
\hline
\end{tabular}

Source: Researcher 2019 


\section{Editon Consortium Journal of Arts, Humanities and Social Studies (ECJAHSS)}

Volume: 01 Issue: 03 | Sep -2019

ISSN: $2663-8525$

Received: 19.08.2019; Accepted 23.08.2019; published: 30.09.2019 at www.editoncpublishing.org

Juma, D. Kimeli et al., Editon Cons. J. Arts., Humanit. S. Stud., Double -Blind Peer Reviewed Journal

Interpersonal relationships in the group are an inescapable reality for all those working in organizations. While they have often been studied from a negative perspective, for many these relationships may facilitate a context in which working individuals can fulfil their "need to belong" (Saim et al., 2015). Performance of members of any organization depends on the ability to effectively interact with their superiors, subordinates and co-workers within the organization and consumers, suppliers and general public outside. Interpersonal relations, therefore is a very important issue involving any organization. Most organizations have people problems rather than business problems. People problems are due to faulty interpersonal relations, which hinder the attainment of organizational goal (Patricia, 2016). Some bad experiences may be experienced due to miscommunication between the groups and their leaders. However, with good communication process members are expected to work with minimal instructions.

On the general type of interpersonal relationships and how largely they contribute towards church development, 52\% strongly agree, 34 agree, $12 \%$ were neutral on the findings while $2 \%$ disagreed and $0 \%$ strongly disagreed.This is because members feel included in the process of decision making. If there are carrying out certain projects in the church, they fully participate at every stage because the own it. In this case they work is done smoothly, where each member of the group is playing their role because they feel they belong. It is also important to note that people have always lived in-group. A good example is families, friends, working groups who share the same values systems, loving, caring and providing for each other for strengthening each other for the benefit of the group. This brings about unity and harmony in the fellowship groups.

The other positive element of fellowship group is that each member has the opportunity to share their views. This brings in the value of each member feeling that they have something to offer, use their talents, gifts and skills to serve. Some people join the group because they want to serve, other wants to be supported to use their time and other resources for the welfare of their fellowship groups. It is in the fellowship meetings where the members discover and grow their talents as they serve together. Patricia (2016) argues that some people with the same issues may join the group not for financial support by more because they are seeking emotional support. In the same way apart from fellowship members serving together, they provide emotional support in fellowship meeting where they support, encourage and share their experiences together. Baird (2018), found out that being part of a small group helps in reducing stress since members share their needs in a free environment and help each other.

According to Gallos and Bass (2003) poor communication within groups may lead to broken relationships hence hindering participation and collaboration. On the other hand, good communication increases understanding within the group members even as they serve together. One of the main benefits of having small groups is that these groups are able to meet the interpersonal needs. This is because members feel included in the process of decisionmaking. One of the main benefits of having small groups is that these groups are able to meet the interpersonal needs. This is achieved through giving the members access 


\section{Editon Consortium Journal of Arts, Humanities and Social Studies (ECJAHSS)}

Volume: 01 Issue: 03 | Sep -2019

ISSN: $2663-8525$

Received: 19.08.2019; Accepted 23.08.2019; published: 30.09.2019 at www.editoncpublishing.org

Juma, D. Kimeli et al., Editon Cons. J. Arts., Humanit. S. Stud., Double -Blind Peer Reviewed Journal

to inclusion, control and support. In terms of inclusion, people have a fundamental drive to be a part of a group and to create and maintain social bonds. Humans have always lived and worked in small groups. Family and friendship groups, shared-interest groups, and activity groups all provide us with a sense of belonging and being included in an in-group. People also join groups because they want to have some control over a decision-making process or to influence the outcome of a group.

Being a part of a group allows people to share opinions and influence others. Conversely, some people join a group to be controlled, because they don't want to be the sole decision maker or leader and instead want to be given a role to follow. Just as we enter into interpersonal relationships because we like someone, we are drawn toward a group when we are attracted to it and/or its members. While these groups may also meet instrumental needs through connections and referrals to resources, they fulfil the interpersonal need for belonging that is a central human need. While procedural and substantive conflict may be more easily expressed because they do not directly, address a person, interpersonal conflict may slowly build as people avoid openly criticizing or confronting others. This is because members feel included in the process of decision-making. If there are carrying out certain projects in the church, they fully participate at every stage because the own it. In this case they work is done smoothly, where each member of the group is playing their role because they feel they belong. It is also important to note that people have always lived in-group. A good example is families, friends, working groups who share the same values systems, loving, caring and providing for each other for strengthening each other for the benefit of the group.
This brings about unity and harmony in the fellowship groups. That sense of belonging is so key and helps people to live a stress-free life. If there is a good interpersonal relationship between the individuals in the group, then the members will have a good time. For example, leaders that are perceived to be good listeners have been associated with employees feeling a sense of togetherness, belonging, social significance as well as inclusion (Alvesson, \& Swevingsson, 2003).

Unity of group members promotes teamwork and aids the development agenda of the organization. Members who related well with each other had good working relationship. The fellowship groups were marked with love for one another and collaboration, which helped churches to realize their goals for growth. Every member participated in the outreach programs organized within fellowship groups as well as by the main church. Rock a group with poor interpersonal relationship on the other hand, will most of the time with conflicts, which slow down the development process of the organization. A good interpersonal relationship among group members also aid in the decision-making process of the group members. Decision-making is a process that most of the time requires more than one person. When members of the team have good interpersonal relationships, they will be able to make decisions which are objective and for the common good of the organization. These decisions will have been thoroughly thought through and will be made after careful considerations and deliberations. Such decisions help the organization as it works towards attaining its goals and objectives (Reich, \& Herschcovis, 2011).

Table 2: Correlation Matrix 
Editon Consortium Publishing

Transforming Scholarly Publishing

\section{Editon Consortium Journal of Arts,} Humanities and Social Studies (ECJAHSS)

Volume: 01 Issue: 03 | Sep -2019

ISSN: $2663-8525$

Received: 19.08.2019; Accepted 23.08.2019; published: 30.09.2019 at www.editoncpublishing.org

Juma, D. Kimeli et al., Editon Cons. J. Arts., Humanit. S. Stud., Double -Blind Peer Reviewed Journal

\begin{tabular}{|l|l|}
\hline & FACTORS AFFECTING YOUTHS BEHAVIOUR \\
\hline Factor 1 & LEADERSHIP \\
\hline Factor 2 & CULTURE \\
\hline Factor 3 & INTERPERSONAL RELATIONSHIP \\
\hline
\end{tabular}

Source: Researcher 2019

A correlation matrix is a statistical test undertaken that is used to measure the strength in the relationship between the variables in a study to establish the positivity or negativity in their relationship i.e. linear relationship.

Table 3: Correlation Matrix Indicating the Relationship Between the Independent Variables

\begin{tabular}{|l|l|l|l|}
\hline FACTORS & F1 & F2 & F3 \\
\hline F1 & 1.000 & 0.587 & .498 \\
\hline F2 & .587 & 1.000 & .601 \\
\hline F3 & .498 & .601 & 1.000 \\
\hline
\end{tabular}

Source: Author, 2019
High correlations were noted between leadership and culture at 0.587 . The study also noted that there were high correlations between culture and interpersonal relationship as shown by coefficients 0.601 . The variables obtained by the correlation analysis clearly indicated a strong positive relationship between our variables, which can safely help us conclude that they have a positive relationship. This means an increase in the value of one variable means an increase in value for the other variable. In a graph, a line indicating a positive linear relationship would show this.

\section{Multiple Regression Analysis}

Our study employed multiple regression analysis to determine the estimating of the relationships among variables. We also used it to understand which among the independent variables are related to the dependent variable, and to explore the forms of these relationships.

Table 4: Multiple Regression Analysis

\begin{tabular}{|l|l|l|l|l|l|l|}
\hline \multicolumn{2}{|l|}{ Regression Statistics } & & & & & \\
\hline Multiple R & 0.089582802 & & & & & \\
\hline R Square R & 0.605015674 & & & & & \\
\hline $\begin{array}{l}\text { Adjusted } \\
\text { Sauare }\end{array}$ & 0.444400903 & & & & & \\
\hline $\begin{array}{l}\text { Standard Error } \\
\text { Observations }\end{array}$ & 5 & & & & & \\
\hline
\end{tabular}


Editon Consortium Publishing

Transforming Scholarly Publishing

\section{Editon Consortium Journal of Arts, Humanities and Social Studies (ECJAHSS)}

Volume: 01 Issue: 03 | Sep -2019

ISSN: $2663-8525$

Received: 19.08.2019; Accepted 23.08.2019; published: 30.09.2019 at www.editoncpublishing.org

Juma, D. Kimeli et al., Editon Cons. J. Arts., Humanit. S. Stud., Double -Blind Peer Reviewed Journal

\begin{tabular}{|l|l|l|l|l|l|l|}
\hline & Df & SS & MS & F & & \\
\hline Regression & 2 & 1.605015674 & 0.802507837 & 4.063492063 & 0.047492163 & \\
\hline Residual & 2 & 0.394984326 & 0.197492163 & & & \\
\hline Total & 4 & 2 & & & & \\
\hline & & & & & & \\
\hline & Coefficients & Standard & t Stat & P-value & Lower $95 \%$ & Upper $95 \%$ \\
\hline Intercept & 0.896551724 & 0.764398064 & 1.172885918 & 0.361624318 & -2.39238769 & 4.185491139 \\
\hline LEADERSHIP & 0.33646818 & 0.422703764 & 0.79599038 & 0.509506953 & -1.482279374 & 2.155215634 \\
\hline CULTURE & 0.020898964 & 0.013113794 & 0.159363815 & 0.888021498 & -0.054334235 & 0.058513964 \\
\hline $\begin{array}{l}\text { INTERPERSONAL } \\
\text { RELATIONSHIPS }\end{array}$ & 0.32646818 & 0.012489654 & 0.045908765 & 0.678923005 & -1.328976054 & 2.144678905 \\
\hline
\end{tabular}

\section{Source: Researcher 2019}

The above gives the overall goodness-of-fit measures:

$\mathrm{R} 2=0.8025$

Correlation between y and y-hat is 0.8958 (when squared gives 0.8025).

Adjusted R2 = R2 - (1-R2) *(k-1) (n-k)=.8025-.1975*2/2 =

0.6050 .

Using the p-value approach

- Do not reject the null hypothesis at level .05 since the pvalue is $>0.05$.

- Do not reject the null hypothesis at level .08 since the pvalue is $>0.05$

- Do not reject the null hypothesis at level .06 since the pvalue is $>0.05$

- Do not reject the null hypothesis at level .08 since the $p$ value is $>0.05$
Our study was working to disapprove the following null hypothesis

$\mathrm{H}^{2}$ - fellowship group'sinterpersonal relationships on church development

The table above indicates that our study got a $\mathrm{P}$ - value > 0.05 , which would mean our findings support the current existing hypothesis. This means that we found that the existing relationship between our independent and dependent variables. Hence, we can conclude that fellowship groups play a role in church development in Kenya 


\section{Editon Consortium Journal of Arts, Humanities and Social Studies (ECJAHSS)}

Volume: 01 Issue: 03 | Sep -2019

ISSN: $2663-8525$

Received: 19.08.2019; Accepted 23.08.2019; published: 30.09.2019 at www.editoncpublishing.org

Juma, D. Kimeli et al., Editon Cons. J. Arts., Humanit. S. Stud., Double-Blind Peer Reviewed Journal

ANOVA (Multiple Comparisons)

Table 5: ANOVA Multiple Comparisons

\begin{tabular}{|c|c|c|c|c|c|}
\hline & $\begin{array}{c}\text { Mean } \\
\text { Differences } \\
(\mathrm{A}-\mathrm{D})\end{array}$ & $\begin{array}{c}\text { Standard } \\
\text { Error }\end{array}$ & Sig & Lower 95\% & Upper 95\% \\
\hline Intercept & 0.896551724 & 0.764398064 & 0.461624318 & -2.39238769 & 4.185491139 \\
\hline LEADERSHIP & 0.011646818 & 0.422703764 & 0.509506953 & -1.482279374 & 2.155215634 \\
\hline CULTURE & 0.020898964 & 0.013113794 & 0.888021498 & -0.054334235 & 0.058513964 \\
\hline $\begin{array}{c}\text { INTERPERSONAL } \\
\text { RELATIONSHIPS }\end{array}$ & 0.026468184 & 0.012489654 & 0.678923005 & -1.328976054 & 2.144678905 \\
\hline
\end{tabular}

Source: Researcher 2019

Multiple linear regression attempts to model the relationship between two or more explanatory variables and a response variable by fitting a linear equation to observed data. Every value of the independent variable $x$ is associated with a value of the dependent variable $y$. Second, it can be used to forecast the effects or impacts of changes. That is, multiple linear regression analysis helps us to understand how much will the dependent variable change when we change the independent variables. The findings in our research project show a positive dependency between the dependent and independent variables, which in analysis shows a positive linear regression.

\section{Conclusion and Recommendations}

The study findings (as shown by positive R, and RSquare) established that there was a strong positive correlation between the fellowship group interpersonal relationships and church growth.
Moreover, the coefficient corresponding to interpersonal relationship was positive meaning that the growth in this area positively affects church growth. In conclusion, the fellowship groups have values, that guide the way they operate where each member have the opportunity to share their views. Members feel that they have something to offer, use their skills to serve. It is in the fellowship meetings where the members discover and grow their talents as they serve together. Baird, (2018)found out that being part of a small group helps in reducing stress since members share their needs in a free environment and help each other. The study recommends that more emphasis should be given to interpersonal growth as this will contribute to the growth and development of the church, which will be a win for both the worshippers, and the church at large. 


\section{Editon Consortium Journal of Arts, Humanities and Social Studies (ECJAHSS)}

Volume: 01 Issue: 03 | Sep -2019

ISSN: 2663-8525

Received: 19.08.2019; Accepted 23.08.2019; published: 30.09.2019 at www.editoncpublishing.org

Juma, D. Kimeli et al., Editon Cons. J. Arts., Humanit. S. Stud., Double -Blind Peer Reviewed Journal

\section{References}

Abraham, B. S. (2014). Research in organizational change and development. New York, Emerald Group Publishing.

Africa Gospel Church Kenya. (2018, June 14). African Gospel church website. Retrieved from http://www.agckenya.org/: http://www.agckenya.org/

Alvesson, M., \& Sveningsson, S. (2003). Managers doing leadership: The extra-ordinarization of the mundane. Human Relations, 56(12), 1435-1459.

Baird, M. (2018). Group Culture.

Bellany, C. D. (2015). Leadership and crisis management in modern organizations. BEPress, Liberty UNivesity.

Cameron, K.S. (2012). Positive leadership: Strategies for extraordinary performance. San Francisco: Berett-Koehler Publishers.

Carl F. G. (2012). Prepare your church for the future. Grand Rapids, Mich: Fleming H. Revell.

Gallos, J., \& Bass, J. (2003). Interpersonal and Group Dynamics. San Francisco: A Wiley Company.

Gerald, J. (2014, December 7). The importance of small groups. Retrieved from: https://urnottheonlyone.com/2016/07/12/the-importance-and-role-of-small-groups-2/

Howerton, R., \& Mannnig, B. (2012). A different kind of tribe: Embracing the new small-group dynamic. NavPress.

Levi, D. (2001). Group dynamics for teams. Thousand Oaks: Sage Publication.

Luthans, F., \& Church, A. (2002) Positive organizational behavior: Developing and managing psychological strengths. Academy of Management, 16, 57-75.

Markus, M.L. (2015). New games, new scoreboards and potential consequences, of big data. Journal of Information Technology, 58-59.

Patricia, O. (2016). Improving Interpersonal relationship in workplaces. IOSR Journal of Research \& Method in Education, 115-125.

Reich, T. C., \& Hershcovis, M. S. (2011). Interpersonal relationships at work. In S. Zedeck (Ed.), APA Handbooks in Psychology. APA handbook of industrial and organizational psychology, Vol. 3. Maintaining, expanding, and contracting the organization (pp. 223-248). Washington, DC, US: American Psychological Association.

Saim, M., Cemberci, M., \& Gunel, D. (2015). Groups and their effects on organizations. European Scientific Journal, 11(32), 12-34.

Toseland, R. W., \& Rivas, R.F. ( 2001). An Introduction Group work Practice .Boston: Allyn

Warren, R. (2018, April 1). 4 practical reasons for small groups. Church Leaders, Retrieved from https://churchleaders.com/smallgroups/small-group-articles/321591-rick-warren-4practical-reasons-small-groups-rick-warren.html 